\title{
Molecular Authentication of the Animal Crude Drug Sailonggu (Bone of Myospalax baileyi)
}

\author{
Caiquan ZHоU, ${ }^{a}$ Kaiya ZHoU, ${ }^{*, a}$ and Shaolai ZHANG ${ }^{b}$ \\ ${ }^{a}$ Jiangsu Key Lab for Bioresource Technology, College of Life Sciences, Nanjing Normal University; Nanjing 210097, \\ China: and ${ }^{b}$ Beijing Tongrentang Medicinal Liquor Factory; Beijing 101149, China. \\ Received April 23, 2004; accepted July 17, 2004
}

Two pairs of allele-specific diagnostic primers (SL1L/SL1H and SL2L/SL2H) for distinguishing the Chinese crude drug Sailonggu (bone of plateau zokor, Myospalax baileyi) from its substitutes were designed based on complete sequences of mitochondrial 12S rRNA and cytochrome $b$ genes of the original animals of Myospalacinae, bamboo rat Rhizomys sinensis and black lipped pika Ochotona curzoniae. Total DNA was extracted from crude drug samples and original animals. Allele-specific diagnostic PCRs were performed using these primers with the total DNA as a template annealing at $65^{\circ} \mathrm{C}$. Positive amplifications were obtained from all DNA templates of Sailonggu and $M$. baileyi, whereas negative amplifications resulted from those of other zokors, the bamboo rat and black lipped pika. These results indicate that Sailonggu samples can be definitely distinguished from their substitutes by diagnostic PCR, and no incorrect discrimination was found under the same reaction conditions. Each of the two diagnostic primer pairs can be used to distinguish crude drug Sailonggu from its substitutes or adulterants. The three Sailonggu samples studied were diagnosed as genuine Sailonggu. In addition, the results of sequence alignment and phylogenetic analysis are congruent with that of the allele-specific diagnostic PCR.

Key words crude drug Sailonggu; Myospalax baileyi; allele-specific diagnostic PCR; molecular authentication; mitochondrial gene sequence

The application of animal medicinal materials has a centuries-old history in China. Zokors (Myospalacinae) were recorded as a type of animal crude drug in Bencaogangmu, a famous work written by Li Shizhen about 400 years ago during the Ming Dynasty, which identified 1892 kinds of medicines. The flesh and bone of the zokors were reported to cure many kinds of inflammation. ${ }^{1)}$ The dried bone of plateau zokor (Myospalax baileyi) is called Sailonggu, and has been used medicinally by local Tibetans in the Qinghai Province in China. ${ }^{2)}$ In the middle of the 1970s, it was found that the Tibetan drug Sailonggu could cure rheumatic diseases and is an ideal substitute for the Chinese crude drug "tiger bone."3,4) Sailong Rheumatic Liquor, made from the bone of plateau zokor, has been produced since 1995 by the Beijing Tongrentang Medicinal Liquor Factory, Beijing Tongrentang Medicine Industry Limited Group.

Plateau zokor (M. baileyi) is found in plateau habitats in Qinghai, Gansu and Sichuan Provinces. ${ }^{5)}$ However, it shares habitats with the Gansu zokor (M. cansus), the bamboo rat (Rhizomys sinensis), and several other rodents such as the black lipped pika (Ochotona curzoniae). Consequently, Sailonggu is mingled with adulterants in the course of crude drug collection. The identification of animal crude drugs has always been problematical because their substitutes or adulterants are very similar to the quality goods, both in morphological characteristics and in organic or inorganic components, especially when cut into pieces. The mtDNA sequences of $12 \mathrm{~S}$ rRNA and cytochrome $b$ (cyt $b$ ) genes have been used successfully by Wang and Zhou ${ }^{6}$ as molecular markers in the authentication of a variety of animal crude drugs. These were investigated in the present study in order to develop molecular genetic markers for the identification of Sailonggu.

\section{MATERIALS AND METHODS}

Sample Collection Twenty-one individuals, representing seven species of zokors of the genus Myospalax, were used in this study (Table 1). One Chinese bamboo rat (Rhizomys sinensis) and one black lipped pika (Ochotona curzoniae) were also included. The original animals of the samples were identified according to morphological characteristics. The crude drug Sailonggu samples were provided by Beijing Tongrentang Medicinal Liquor Factory, Beijing Tongrentang Medicine Industry Limited Group. All specimens are deposited in the collection of Nanjing Normal University $(\mathrm{NNU})$. Tissue samples derived from muscle are preserved in 95\% ethanol.

DNA Extraction Total genomic DNA was extracted from the ethanol preserved muscle samples as described in Sambrook et $\mathrm{al}^{7)}$ For isolation of total DNA from the crude drug Sailonggu, about $1.0 \mathrm{~g}$ bone pieces taken from each sample were washed with water and $\mathrm{ddH}_{2} \mathrm{O}$ twice, respectively, and dried at $80^{\circ} \mathrm{C}$. The bone pieces were exposed under a $20 \mathrm{~W}$ ultraviolet lamp for $40 \mathrm{~min}$ in order to remove exo-DNA contaminations. The samples were ground to a fine powder using liquid nitrogen. One milliliter of $0.5 \mathrm{M}$ EDTA (pH 8.0) was added to $0.5 \mathrm{~g}$ bone powder in a $1.5 \mathrm{ml}$ Eppendorf tube, and incubated for $72 \mathrm{~h}$ at $56^{\circ} \mathrm{C}$, then centrifuged for $5 \mathrm{~min}$ at $5000 \mathrm{~g}$ in $4{ }^{\circ} \mathrm{C}$ to change EDTA twice in the course of incubation. The sample was then incubated for $4 \mathrm{~h}$ at $65^{\circ} \mathrm{C}$ in $0.5 \mathrm{ml}$ of lysis buffer $(0.5 \mathrm{M}$ EDTA, $10 \mathrm{~mm}$ Tris- $\mathrm{HCl}(\mathrm{pH} 8.5), 0.5 \%$ SDS, $200 \mu \mathrm{g} / \mathrm{ml}$ Proteinase K). After digestion, DNA was extracted with phenol and chloroform and precipitated with ethanol. The final volume of the extract varied between $100-120 \mu \mathrm{l}$.

PCR and Sequence Analysis Two pairs of primers, L14724 (5' -C GAA GCT TGA TAT GAA AAA CCA TCG TTG-3') and H15917 (5'-C GGA ATT CCA TTT TTG GTT 
Table 1. Samples of Original Animals and Crude Drugs Used in This Study

\begin{tabular}{|c|c|c|c|c|c|}
\hline \multirow{2}{*}{ Species } & \multirow{2}{*}{$\operatorname{Code}^{a)}$} & \multirow{2}{*}{ Locality } & \multirow{2}{*}{ Catalogue no. } & \multicolumn{2}{|c|}{ GenBank Accession no. } \\
\hline & & & & $12 \mathrm{~S}$ rDNA & Cyt $b$ DNA \\
\hline Myospalax baileyi 1 & 4 & Xihai, Qinghaihu & NNU M9901 & AF326236 & AF326255 \\
\hline M. baileyi 2 & 5 & Sangke, Gansu & NNU M9902 & AF326235 & AF326256 \\
\hline M. baileyi 6 & 6 & ditto & NNU M9915 & & \\
\hline M. baileyi 7 & 7 & Qinghai & NNU M9916 ${ }^{b)}$ & & \\
\hline M. baileyi 8 & 8 & Sangke, Gansu & NNU M9917 ${ }^{b)}$ & & \\
\hline M. cansus 1 & 11 & Ledu, Qinghai & NNU M9903 & AF326240 & AF326260 \\
\hline M. cansus 2 & & Qinghai & NNU M9904 & AF326241 & AF326261 \\
\hline M. cansus 3 & & Guyuan, Ningxia & NNU M 9906 & AF326243 & AF326263 \\
\hline M. cansus 4 & & Ditto & NNU M9905 & & AF326262 \\
\hline M. cansus 5 & & Qingshui, Gansu & NNU M 9907 & AF326242 & \\
\hline M. rothschildi 1 & 12 & Wanyuan, Sichuan & NNU M9912 & AF326246 & AF326267 \\
\hline M. rothschildi 2 & & Ditto & NNU M9913 & AF326247 & AF326268 \\
\hline M. fontanieri 1 & 15 & Chicheng, Hebei & NNU M9908 & AF326244 & \\
\hline M. fontanieri 2 & & Ditto & NNU M 9909 & & AF326264 \\
\hline M. fontanieri 3 & & Ditto & NNU M 9910 & & AF326265 \\
\hline M. fontanieri 4 & & Ditto & NNU M9911 & AF326245 & AF326266 \\
\hline M. psilurus 1 & 14 & Daxing, Beijing & NNU M9920 & AF326249 & AF326270 \\
\hline M. psilurus 2 & & Ditto & NNU M9921 & AF326250 & AF326271 \\
\hline M. aspalax 1 & 16 & Balinzuoqi, Inner Mogolia & NNU M9922 & AF326251 & AF326272 \\
\hline M. aspalax 2 & & Ditto & NNU M9923 & AF326252 & \\
\hline M. rufescens & 17 & Ningshaan, Shaanxi & NNU M9914 & AF326248 & AF326269 \\
\hline Rhizomys sinensis & 13 & ditto & NNU M9925 & AF326254 & AF326274 \\
\hline Ochotona curzoniae & 10 & Hudong, Qinghai & NNU M9924 & AF326253 & AF326273 \\
\hline Sailonggu 1 & 1 & & NNU Md9901 & AF326238 & AF326258 \\
\hline Sailonggu 2 & 2 & & NNU Md9902 & AF326239 & AF326259 \\
\hline Sailonggu 3 & 3 & & NNU Md9903 & AF326240 & AF326257 \\
\hline
\end{tabular}

a) Codes identical to those in Fig. 3. b) For allele-specific diagnostic PCR only.

Table 2. Diagnostic Primers Designed for Amplification and Sequencing of Mt 12S rRNA and Cyt $b$ Gene Fragments

\begin{tabular}{cl}
\hline \hline Name & \multicolumn{1}{c}{ Sequence $5^{\prime}-3^{\prime}$} \\
\hline SL1-L & GAAACAGCAGTGATAAAAATTAAGCC \\
SL1-H & CTGGCGGGTAATTTTGTTGGAAATT \\
SL2-L & CATTCTCATCAGTAACCCATATTTGC \\
SL2-H & ATTCATTCTACTAGGGAGGTTCCTACA \\
\hline
\end{tabular}

TAC AAG-3') for complete mitochondrial cyt $b$ gene, and LtRNA $^{\text {Phe }}$ (5'-AA AGC AAA GCA CTG AAA ATG-3') and H-tRNA ${ }^{\text {Val }}$ (5'-G CTA GGG TTA GTT CAA AGT GTT-3') for complete $12 \mathrm{~S}$ rRNA gene, were used in the present study. Primer L14724 was cited from Kocher et al., ${ }^{8)}$ and the other three were designed by the authors. Two other primer pairs, L1091 (5'-AA AAA GCT TCA AAC TGG GAT TAG ATA CCC CAC TAT- $\left.3^{\prime}\right)$ and H1478 (5'-T GAC TGC AGA GGG TGA CGG GCG GTG TGT-3'), and L15513 (5'-CT AGG AGA CCC TGA CAA CTA-3' ${ }^{\prime}{ }^{8}$ and H15917, were used in this study. We failed to amplify the complete sequences of the $12 \mathrm{~S}$ rRNA and cyt $b$ genes from the crude drug samples, because the DNA of the crude drug Sailonggu was degraded in varying degrees. Therefore, the primer pair L1091/H1478 was used for the amplification of the 12S rRNA gene fragment to prove the quality of genomic DNA in subsequent diagnostic PCR and in sequencing the crude drug samples. L15513/H15917 was used for amplification and sequencing of the Cyt $b$ gene fragments of the crude drug samples.

The amplification was carried out on a PTC-200 thermocycler (MJ Research) in a $30 \mu$ l reaction mixture containing
$10 \mathrm{~mm}$ Tris- $\mathrm{HCl}$ (pH 8.3), $1.5 \mathrm{~mm} \mathrm{MgCl}_{2}, 50 \mathrm{~mm} \mathrm{KCl}$, $150 \mathrm{~mm}$ of each dNTP, $0.3 \mathrm{~mm}$ of each primer (synthesized by TaKaRa), $1.0 \mu \mathrm{l}$ (about $100 \mathrm{ng}$ ) template DNA, and $1 \mathrm{U}$ Taq DNA polymerase (Promega). The reaction mixtures were denatured at $95^{\circ} \mathrm{C}$ for $5 \mathrm{~min}$ and subjected to 30 cycles of $40 \mathrm{~s}$ at $95^{\circ} \mathrm{C}, 1 \mathrm{~min}$ at $55^{\circ} \mathrm{C}, 1.5 \mathrm{~min}$ at $72^{\circ} \mathrm{C}$, and a final extension step of $7 \mathrm{~min}$ at $72^{\circ} \mathrm{C}$. Amplified products were purified using Wizard ${ }^{\mathrm{TM}}$ PCR Prep DNA Kit (Promega) according to the manufacturer's instructions, then the two strands were sequenced directly with PRISM ${ }^{\mathrm{TM}}$ BigDye Terminator Ready Reaction Kit (Applied Biosystems) on an ABI 310 Genetic Analyzer (Perkin Elmer).

Data Analysis Sequences of fragments of the two genes were aligned in ClustalX $1.8^{9)}$ and adjusted manually, taking into account the secondary structure of the gene. Relationships among taxa were investigated using analysis of distance data derived from nucleotide substitutions among taxa employing Kimura's two-parameter model. ${ }^{10)}$ UPGMA analysis of the 12S rRNA and cyt $b$ datasets was carried out by Molecular Evolutionary Genetics Analysis (MEGA 2.1). ${ }^{11)}$ Gaps were coded as missing. Ochotona curzoniae and Rhizomys sinensis were chosen as outgroup taxa. Robustness of the inferred phylogeny was evaluated by bootstrap resampling with 1000 replications.

Allele-Specific Diagnostic PCR Based on sequences of the two mitochondrial DNA genes of 7 species of zokors, Rhizomys sinensis and Ochotona curzoniae, two pairs of primers, SL1L/SL1H and SL2L/SL2H (Table 2), were designed for diagnostic PCR. Both primer pairs are specific for M. baileyi only. The former amplify a $338 \mathrm{bp}$ DNA segment of the $12 \mathrm{~S}$ rRNA gene, and the latter a $320 \mathrm{bp}$ DNA segment of the Cyt $b$ gene, respectively. The reaction system of diag- 
Table 3. Variable Sites Found among Partial Sequences of 12S rRNA Gene of the Original Animals and Crude Drug Sailonggu (Dashes Denote Gap)

\begin{tabular}{|c|c|c|c|c|c|c|c|c|c|c|c|c|c|c|c|c|}
\hline & & & 1 & 1 & 1 & 2 & 2 & 2 & 2 & 2 & 2 & 2 & 2 & 3 & 3 & 3 \\
\hline & 3 & 9 & 5 & 8 & 9 & 0 & 1 & 2 & 5 & 6 & 7 & 8 & 9 & 5 & 7 & 8 \\
\hline M. psilurus 1,2 & $\mathrm{~T}$ & G & $\mathrm{T}$ & A & G & $\mathrm{C}$ & A & A & - & - & A & A & $\mathrm{C}$ & $\mathrm{T}$ & $\mathrm{T}$ & $\mathrm{C}$ \\
\hline M. aspalax 1,2 & & & & & & $\mathrm{~T}$ & $\mathrm{G}$ & & - & - & & & & & & \\
\hline M. fontanieri 1,2 & & & & & & $\mathrm{~T}$ & G & & - & - & $\mathrm{T}$ & $\mathrm{C}$ & & A & & \\
\hline M. cansus 1,2 & & & & & & $\mathrm{~T}$ & G & & - & - & $\mathrm{T}$ & $\mathrm{C}$ & & $\mathrm{A}$ & & \\
\hline M. cansus 3,5 & & & & & & $\mathrm{~T}$ & $\mathrm{G}$ & & - & - & $\mathrm{T}$ & $\mathrm{C}$ & & A & & \\
\hline M. rufescens & & & & & & $\mathrm{T}$ & $\mathrm{G}$ & & - & - & $\mathrm{C}$ & $\mathrm{C}$ & & $\mathrm{A}$ & & \\
\hline M. rothschildi 1,2 & & & & & & $\mathrm{~T}$ & G & & - & - & $\mathrm{T}$ & $\mathrm{C}$ & & $\mathrm{A}$ & & \\
\hline M. baileyi 1,2 ; Sailonggu 2, 3 & & & & & & $\mathrm{~T}$ & & & - & - & $\mathrm{T}$ & $\mathrm{C}$ & & A & & $\mathrm{T}$ \\
\hline Sailonggu 1 & & & & & & $\mathrm{~T}$ & & & - & - & $\mathrm{T}$ & $\mathrm{C}$ & & A & & $\mathrm{T}$ \\
\hline R. sinensis & & & $\mathrm{C}$ & & & $\mathrm{T}$ & & & $\mathrm{C}$ & $\mathrm{T}$ & $\mathrm{T}$ & $\mathrm{T}$ & $\mathrm{T}$ & $\mathrm{A}$ & & $\mathrm{T}$ \\
\hline \multirow[t]{4}{*}{ O. curzoniae } & $\mathrm{C}$ & A & $\mathrm{C}$ & $\mathrm{G}$ & A & $\mathrm{T}$ & & G & A & $\mathrm{C}$ & & - & $\mathrm{T}$ & A & $\mathrm{C}$ & $\mathrm{T}$ \\
\hline & & & & & & & & & 1 & 1 & 1 & 1 & 1 & 1 & 1 & 1 \\
\hline & 3 & 4 & 4 & 6 & 6 & 6 & 9 & 9 & 0 & 0 & 0 & 1 & 1 & 2 & 3 & 3 \\
\hline & 9 & 0 & 1 & 0 & 2 & 3 & 0 & 6 & 0 & 1 & 2 & 8 & 9 & 9 & 7 & 9 \\
\hline M. psilurus 1,2 & G & $\mathrm{C}$ & $\mathrm{C}$ & $\mathrm{C}$ & $\mathrm{C}$ & $\mathrm{C}$ & A & $\mathrm{T}$ & $\mathrm{T}$ & $\mathrm{G}$ & $\mathrm{T}$ & $\mathrm{C}$ & $\mathrm{T}$ & G & $\mathrm{C}$ & A \\
\hline M. aspalax 1,2 & $\mathrm{~A}$ & & & & & & & & & & & & & A & & \\
\hline M. fontanieri 1,2 & $\mathrm{~A}$ & & & & & & & & & & & & & A & & \\
\hline M. cansus 1,2 & A & & & & & & & & & & & & & & & \\
\hline M. cansus 3,5 & $\mathrm{~A}$ & & & & & $\mathrm{~T}$ & & & & & & & & & & \\
\hline M. rufescens & $\mathrm{A}$ & & & & & & & & & & & & & & & \\
\hline M. rothschildi 1,2 & A & & & & & & & & & & & & & & & \\
\hline M. baileyi 1,$2 ;$ Sailonggu 2,3 & $\mathrm{~A}$ & & & & & & & & & & & & & & & \\
\hline Sailonggu 1 & A & & & & & & & & & & & & & & & \\
\hline R. sinensis & A & & $\mathrm{T}$ & A & $\mathrm{T}$ & & & $\mathrm{C}$ & & & & $\mathrm{A}$ & G & A & $\mathrm{T}$ & \\
\hline \multirow[t]{4}{*}{ O. curzoniae } & $\mathrm{A}$ & $\mathrm{T}$ & $\mathrm{T}$ & A & & A & $\mathrm{G}$ & & $\mathrm{C}$ & - & $\mathrm{C}$ & & & A & & $\mathrm{T}$ \\
\hline & 1 & 1 & 1 & 1 & 1 & 1 & 1 & 1 & 1 & 1 & 1 & 1 & 2 & 2 & 2 & 2 \\
\hline & 4 & 4 & 5 & 5 & 5 & 6 & 6 & 8 & 8 & 9 & 9 & 9 & 0 & 0 & 0 & 0 \\
\hline & 0 & 5 & 2 & 3 & 8 & 1 & 9 & 3 & 8 & 5 & 6 & 7 & 2 & 3 & 4 & 5 \\
\hline M. psilurus 1,2 & $\mathrm{C}$ & $\mathrm{T}$ & $\mathrm{C}$ & $\mathrm{C}$ & $\mathrm{T}$ & $\mathrm{T}$ & $\mathrm{A}$ & $\mathrm{C}$ & G & G & $\mathrm{T}$ & $\mathrm{C}$ & A & $\mathrm{C}$ & $\mathrm{C}$ & $\mathrm{C}$ \\
\hline M. aspalax 1,2 & & & & & & & & $\mathrm{~T}$ & & & & & & & $\mathrm{~T}$ & \\
\hline M. fontanieri 1,2 & $\mathrm{~T}$ & & & & & & & $\mathrm{~T}$ & & & & & $\mathrm{~T}$ & & & A \\
\hline M. cansus 1,2 & $\mathrm{~T}$ & & & & & & & $\mathrm{~T}$ & & & & & $\mathrm{~T}$ & & & A \\
\hline M. cansus 3,5 & $\mathrm{~T}$ & & & & & & & $\mathrm{~T}$ & & & & & $\mathrm{~T}$ & & & A \\
\hline M. rufescens & $\mathrm{T}$ & & & & & & & $\mathrm{T}$ & & & & & $\mathrm{T}$ & & & A \\
\hline M. rothschildi 1,2 & $\mathrm{~T}$ & & & & & & & $\mathrm{~T}$ & & & & & $\mathrm{~T}$ & & & A \\
\hline M. baileyi 1,$2 ;$ Sailonggu 2, 3 & & & & & & & & $\mathrm{~T}$ & & & & & $\mathrm{~T}$ & & & $\mathrm{~A}$ \\
\hline Sailonggu 1 & $\mathrm{~T}$ & & & & & & & $\mathrm{~T}$ & & & & & $\mathrm{~T}$ & & & $\mathrm{~A}$ \\
\hline$R$. sinensis & $\mathrm{T}$ & & $\mathrm{T}$ & & & & & $\mathrm{T}$ & A & & & & & A & & $\mathrm{A}$ \\
\hline \multirow[t]{4}{*}{ O. curzoniae } & $\mathrm{T}$ & $\mathrm{C}$ & & $\mathrm{T}$ & $\mathrm{C}$ & $\mathrm{C}$ & G & $\mathrm{T}$ & A & A & A & A & $\mathrm{C}$ & G & $\mathrm{T}$ & $\mathrm{A}$ \\
\hline & 2 & 2 & 2 & 2 & 2 & 2 & 2 & 2 & 2 & 2 & 2 & 2 & 2 & 2 & 2 & 2 \\
\hline & 0 & 0 & 1 & 1 & 1 & 2 & 2 & 2 & 2 & 2 & 2 & 2 & 3 & 5 & 5 & 6 \\
\hline & 6 & 7 & 1 & 5 & 9 & 0 & 3 & 4 & 5 & 6 & 7 & 9 & 4 & 6 & 9 & 0 \\
\hline M. psilurus 1,2 & A & $\mathrm{T}$ & G & A & $\mathrm{C}$ & G & $\mathrm{T}$ & - & A & A & $\mathrm{C}$ & G & $\mathrm{T}$ & $\mathrm{T}$ & G & $\mathrm{G}$ \\
\hline M. aspalax 1,2 & & & & & & & & - & & & & A & & & & \\
\hline M. fontanieri 1,2 & & & & & $\mathrm{~T}$ & & - & - & & & $\mathrm{T}$ & & & & & A \\
\hline M. cansus 1,2 & & & & & $\mathrm{~T}$ & & - & - & & & $\mathrm{T}$ & & & & & $\mathrm{A}$ \\
\hline M. cansus 3,5 & & & A & & $\mathrm{T}$ & & - & - & & & $\mathrm{T}$ & & & & & $\mathrm{A}$ \\
\hline M. rufescens & & & & & $\mathrm{T}$ & & - & - & & & $\mathrm{T}$ & & & & & $\mathrm{A}$ \\
\hline M. rothschildi 1,2 & & & & & $\mathrm{~T}$ & & - & - & & & $\mathrm{T}$ & & & & & A \\
\hline M. baileyi 1, 2; Sailonggu 2, 3 & & & & & $\mathrm{~T}$ & & - & - & & & $\mathrm{T}$ & & & & & $\mathrm{A}$ \\
\hline Sailonggu 1 & & & & & & & - & - & & & $\mathrm{T}$ & & & & & A \\
\hline$R$. sinensis & & $\mathrm{C}$ & A & $\mathrm{C}$ & $\mathrm{T}$ & & & $\mathrm{T}$ & $\mathrm{T}$ & $\mathrm{T}$ & & $\mathrm{A}$ & & & & A \\
\hline \multirow[t]{4}{*}{ O. curzoniae } & G & $\mathrm{C}$ & A & $\mathrm{T}$ & $\mathrm{T}$ & A & - & - & $\mathrm{C}$ & $\mathrm{C}$ & & A & A & $\mathrm{C}$ & $\mathrm{A}$ & \\
\hline & 2 & 2 & 2 & 2 & 2 & 2 & 2 & 2 & 2 & 2 & 2 & 2 & 2 & 3 & 3 & 3 \\
\hline & 6 & 6 & 6 & 7 & 8 & 8 & 9 & 9 & 9 & 9 & 9 & 9 & 9 & 0 & 0 & 0 \\
\hline & 6 & 7 & 9 & 0 & 8 & 9 & 0 & 1 & 2 & 3 & 4 & 6 & 9 & 0 & 1 & 2 \\
\hline M. psilurus 1,2 & A & A & G & $\mathrm{C}$ & A & A & $\mathrm{T}$ & $\mathrm{T}$ & $\mathrm{T}$ & A & $\mathrm{G}$ & A & $\mathrm{T}$ & - & - & $\mathrm{C}$ \\
\hline M. aspalax 1,2 & & & & & $\mathrm{~T}$ & & & & A & & & & & - & - & $\mathrm{T}$ \\
\hline M. fontanieri 1,2 & & & & & & & $\mathrm{C}$ & & & & & & & - & - & $\mathrm{T}$ \\
\hline M. cansus 1,2 & & & & & & G & & & & & & & & - & - & \\
\hline
\end{tabular}


Table 3. (Continued)

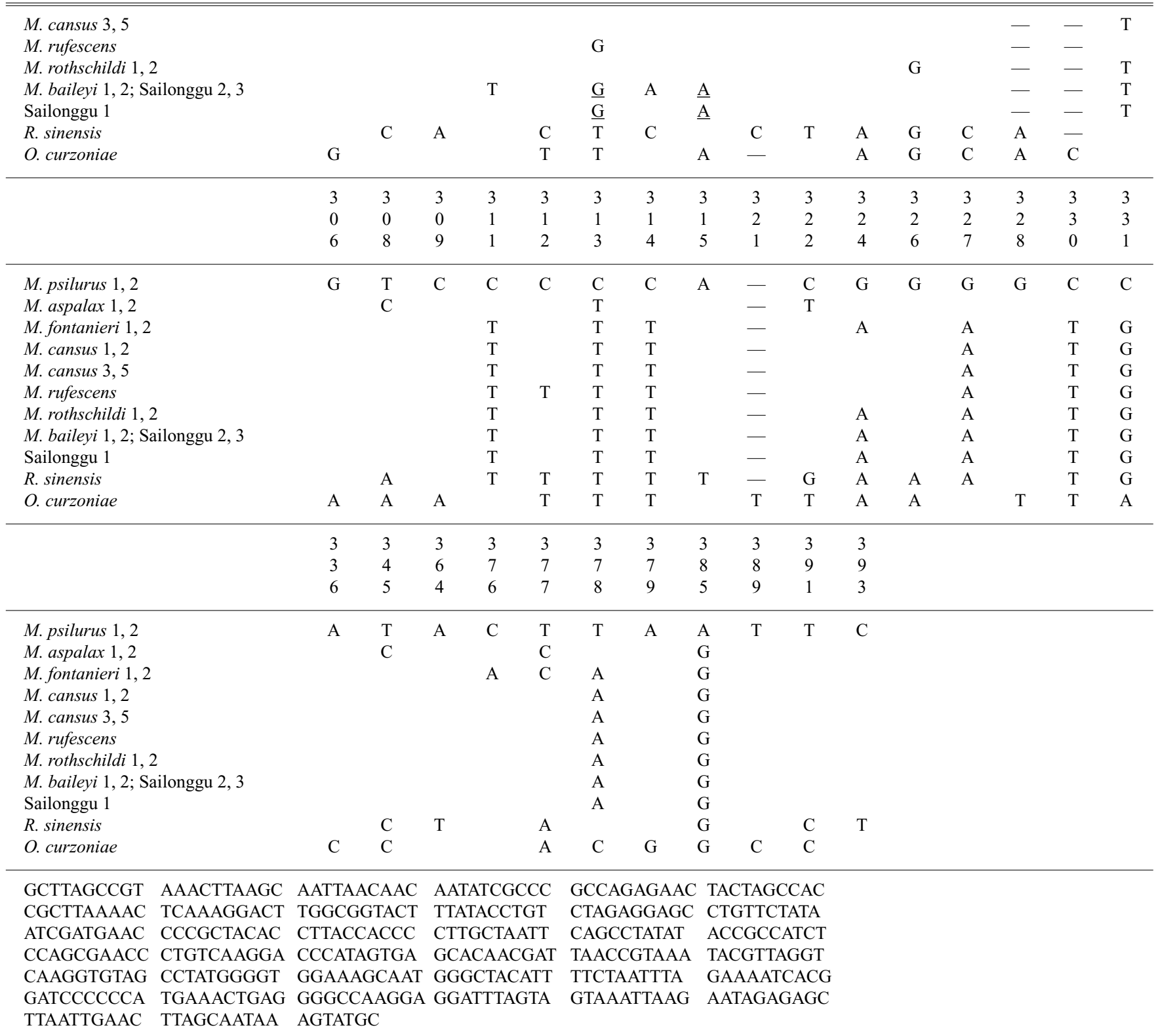

Mutational sites and specific diagnostic sites (underlined below the capital) used to authenticate crude drug Sailonggu are indicated in the Table, with the 387 bp fragment sequence of M. psilurus listed below.

nostic PCR is the same as mentioned above. The diagnostic PCR conditions are as follows: denaturing at $95^{\circ} \mathrm{C}$ for $4 \mathrm{~min}$, then 30 cycles of $20 \mathrm{~s}$ at $95^{\circ} \mathrm{C}, 25 \mathrm{~s}$ at $65^{\circ} \mathrm{C}, 10 \mathrm{~s}$ at $72^{\circ} \mathrm{C}$, and a final extension of $2 \mathrm{~min}$ at $72^{\circ} \mathrm{C}$. Then, $5 \mathrm{ml}$ of the reaction mixture was used for electrophoresis in $2.0 \% \mathrm{TBE}$ agarose gel stained by ethidium bromide, and the results were recorded with a Gel Documentation System (GDS7600, UVP).

\section{RESULTS}

12S rRNA and Cyt $b$ Datasets Seventeen complete sequences of $12 \mathrm{~S}$ rRNA on one hand and cyt $b$ on the other for 7 species of zokors and 2 outgroup taxa were obtained. In addition, 3 partial sequences of the two genes, respectively, for crude drug Sailonggu were obtained (see Table 1 for GenBank accession numbers). The aligned partial sequences of
12S rRNA fragments of the original animals and Sailonggu consisted of a total of 393 sites, including 107 variable sites (Table 3). There are two fixed nucleotide substitutions in the 12S rRNA gene (position 289, 291) for all M. baileyi and Sailonggu samples, the " $A$ " being substituted for "G," and "T" for "A," respectively. The aligned cyt $b$ fragments of the original animals and Sailonggu consist of a total of 370 sites, including 170 variable sites (Table 4). There are also two substitutions in the cyt $b$ gene (position 79,334 ) for $M$. baileyi and Sailonggu, the "C" being substituted for "T," and "A" for "C," respectively. Therefore, they were referred to as specific diagnostic genetic markers for identification of the crude drug. The three crude drug samples were determined as qualified Sailonggu, according to these diagnostic markers.

The divergence between any of the three crude drugs and the original animal of $M$. baileyi ranged from 0 to 0.011 in 
Table 4. Variable Sites Found among Partial Sequences of Cyt $b$ Gene of the Original Animals and Crude Drug Sailonggu (Dashes Denote Gap)

\begin{tabular}{|c|c|c|c|c|c|c|c|c|c|c|c|c|c|c|c|c|c|c|c|}
\hline & 1 & 4 & 7 & 8 & 9 & $\begin{array}{l}1 \\
0\end{array}$ & $\begin{array}{l}1 \\
3\end{array}$ & $\begin{array}{l}1 \\
6\end{array}$ & 1 & $\begin{array}{l}1 \\
9\end{array}$ & 2 & 2 & $\begin{array}{l}2 \\
5\end{array}$ & $\begin{array}{l}2 \\
8\end{array}$ & 3 & 3 & $\begin{array}{l}3 \\
7\end{array}$ & 4 & 4 \\
\hline M. psilurus 1 & $\mathrm{C}$ & $\mathrm{C}$ & $\mathrm{A}$ & $\mathrm{G}$ & $\mathrm{C}$ & $\mathrm{A}$ & $\mathrm{C}$ & $\mathrm{A}$ & $\mathrm{C}$ & $\mathrm{T}$ & $\mathrm{A}$ & $\mathrm{C}$ & $\mathrm{A}$ & $\mathrm{A}$ & $\mathrm{A}$ & $\mathrm{T}$ & $\mathrm{C}$ & $\mathrm{A}$ & $\mathrm{T}$ \\
\hline M. psilurus 2 & & & & & & & & & & $\mathrm{C}$ & & & & & & & & & \\
\hline M. aspalax 1 & & & $\mathrm{G}$ & & & & & & & $\mathrm{A}$ & $\mathrm{G}$ & $\mathrm{T}$ & & & $\mathrm{C}$ & & & & \\
\hline M. fontanieri 2 & $\mathrm{~T}$ & & & & & $\mathrm{~T}$ & & & $\mathrm{~T}$ & $\mathrm{~A}$ & & $\mathrm{~T}$ & & & $\mathrm{C}$ & & & & \\
\hline M. fontanieri 3 & $\mathrm{~T}$ & & & & & $\mathrm{~T}$ & & & $\mathrm{~T}$ & $\mathrm{~A}$ & & $\mathrm{~T}$ & & & $\mathrm{C}$ & & & & \\
\hline M. fontanieri 4 & $\mathrm{~T}$ & & & & & $\mathrm{~T}$ & & & $\mathrm{~T}$ & $\mathrm{~A}$ & & $\mathrm{~T}$ & & & $\mathrm{C}$ & & & & \\
\hline M. baileyi 1 & $\mathrm{~T}$ & & & $\mathrm{C}$ & $\mathrm{G}$ & & & & & $\mathrm{A}$ & & & & & $\mathrm{C}$ & & $\mathrm{T}$ & & \\
\hline M. baileyi 2 & $\mathrm{~T}$ & & & & & & & & & $\mathrm{~A}$ & & & & & $\mathrm{C}$ & & $\mathrm{T}$ & & \\
\hline Sailonggu 2 & $\mathrm{~T}$ & & & & & & & & & $\mathrm{~A}$ & & & & & $\mathrm{C}$ & & $\mathrm{T}$ & & \\
\hline Sailonggu 3 & $\mathrm{~T}$ & & & & & & & & & $\mathrm{~A}$ & & & & & $\mathrm{C}$ & & $\mathrm{T}$ & & \\
\hline Sailonggu 1 & $\mathrm{~T}$ & & & & & & & & & $\mathrm{~A}$ & & & & & $\mathrm{C}$ & & $\mathrm{T}$ & & \\
\hline M. cansus 1,2 & $\mathrm{~T}$ & $\mathrm{~T}$ & & & & & & & & $\mathrm{~A}$ & & & & & $\mathrm{C}$ & & $\mathrm{T}$ & & \\
\hline M. cansus 4 & $\mathrm{~T}$ & $\mathrm{~T}$ & & & & & & & & $\mathrm{~A}$ & & & & & $\mathrm{C}$ & & $\mathrm{T}$ & & \\
\hline M. cansus 3 & $\mathrm{~T}$ & $\mathrm{~T}$ & & & & & & & & $\mathrm{~A}$ & & & & & $\mathrm{C}$ & & $\mathrm{T}$ & G & \\
\hline M. rufescens & $\mathrm{T}$ & & & & & & & & & $\mathrm{A}$ & & $\mathrm{T}$ & & & $\mathrm{C}$ & $\mathrm{C}$ & $\mathrm{T}$ & & \\
\hline M. rothschildi 1 & $\mathrm{~T}$ & & & & & & & & & $\mathrm{~A}$ & & $\mathrm{~T}$ & & & $\mathrm{C}$ & $\mathrm{C}$ & $\mathrm{T}$ & & \\
\hline M. rothschildi 2 & $\mathrm{~T}$ & & & & & & & & & $\mathrm{~A}$ & & $\mathrm{~T}$ & & & $\mathrm{C}$ & & $\mathrm{T}$ & & \\
\hline$R$. sinensis & $\mathrm{T}$ & & $\mathrm{C}$ & & $\mathrm{T}$ & & $\mathrm{T}$ & $\mathrm{T}$ & $\mathrm{T}$ & $\mathrm{C}$ & & & & & $\mathrm{C}$ & $\mathrm{C}$ & $\mathrm{T}$ & & $\mathrm{G}$ \\
\hline \multirow[t]{4}{*}{ O. curzoniae } & $\mathrm{T}$ & $\mathrm{T}$ & $\mathrm{C}$ & & $\mathrm{C}$ & & & & & $\mathrm{C}$ & & & $\mathrm{C}$ & $\mathrm{G}$ & & $\mathrm{C}$ & $\mathrm{T}$ & & \\
\hline & & & & & & & & & & & & & & & & & 1 & 1 & 1 \\
\hline & 5 & 5 & 5 & 6 & 6 & 6 & 7 & 7 & 7 & 7 & 7 & 8 & 8 & 8 & 9 & 9 & 0 & 0 & 0 \\
\hline & 2 & 5 & 8 & 1 & 4 & 7 & 0 & 3 & 4 & 6 & 9 & 2 & 5 & 8 & 1 & 7 & 0 & 3 & 6 \\
\hline M. psilurus 1 & $\mathrm{~T}$ & $\mathrm{C}$ & $\mathrm{C}$ & $\mathrm{C}$ & $\mathrm{C}$ & $\mathrm{C}$ & $\mathrm{A}$ & $\mathrm{C}$ & $\mathrm{C}$ & $\mathrm{A}$ & $\mathrm{C}$ & $\mathrm{T}$ & $\mathrm{T}$ & $\mathrm{C}$ & $\mathrm{T}$ & $\mathrm{A}$ & $\mathrm{A}$ & $\mathrm{A}$ & $\mathrm{C}$ \\
\hline M. psilurus 2 & & & & & & & & & & & & & & & & & & & \\
\hline M. aspalax 1 & $\mathrm{C}$ & $\mathrm{T}$ & & & & & & & & & & $\mathrm{A}$ & $\mathrm{C}$ & $\mathrm{T}$ & & $\mathrm{T}$ & & $\mathrm{C}$ & $\mathrm{T}$ \\
\hline M. fontanieri 2 & & $\mathrm{~T}$ & & $\mathrm{~T}$ & & & $\mathrm{C}$ & $\mathrm{T}$ & & & & & $\mathrm{C}$ & $\mathrm{A}$ & & & $\mathrm{C}$ & $\mathrm{T}$ & $\mathrm{A}$ \\
\hline M. fontanieri 3 & & $\mathrm{~T}$ & & $\mathrm{~T}$ & & & $\mathrm{C}$ & $\mathrm{T}$ & & & & & $\mathrm{C}$ & $\mathrm{A}$ & & & $\mathrm{C}$ & $\mathrm{T}$ & $\mathrm{A}$ \\
\hline M. fontanieri 4 & & $\mathrm{~T}$ & & $\mathrm{~T}$ & & & $\mathrm{C}$ & $\mathrm{T}$ & & & & & $\mathrm{C}$ & $\mathrm{A}$ & & & $\mathrm{C}$ & $\mathrm{T}$ & $\mathrm{A}$ \\
\hline M. baileyi 1 & & & $\mathrm{~T}$ & & & & $\mathrm{~T}$ & & $\mathrm{~T}$ & & $\underline{T}$ & & & $\mathrm{~A}$ & $\mathrm{C}$ & & & $\mathrm{T}$ & $\mathrm{A}$ \\
\hline M. baileyi 2 & & & $\mathrm{~T}$ & & & & $\mathrm{~T}$ & & $\mathrm{~T}$ & & $\overline{\mathrm{T}}$ & & & $\mathrm{A}$ & $\mathrm{C}$ & & & $\mathrm{T}$ & $\mathrm{A}$ \\
\hline Sailonggu 2 & & & $\mathrm{~T}$ & & & & $\mathrm{~T}$ & & $\mathrm{~T}$ & & $\underline{\mathrm{T}}$ & & & $\mathrm{A}$ & $\mathrm{C}$ & & & $\mathrm{T}$ & $\mathrm{A}$ \\
\hline Sailonggu 3 & & & $\mathrm{~T}$ & & & & $\mathrm{~T}$ & & $\mathrm{~T}$ & & $\underline{\mathrm{T}}$ & & & $\mathrm{A}$ & $\mathrm{C}$ & & & $\mathrm{T}$ & $\mathrm{A}$ \\
\hline Sailonggu 1 & & $\mathrm{~T}$ & $\mathrm{~T}$ & & & & $\mathrm{~T}$ & & $\mathrm{~T}$ & & $\underline{\mathrm{T}}$ & & & A & $\mathrm{C}$ & & & $\mathrm{T}$ & A \\
\hline M. cansus 1,2 & $\mathrm{C}$ & $\mathrm{T}$ & $\mathrm{T}$ & & & $\mathrm{T}$ & $\mathrm{T}$ & & $\mathrm{T}$ & & & & $\mathrm{C}$ & $\mathrm{A}$ & $\mathrm{C}$ & $\mathrm{T}$ & $\mathrm{T}$ & $\mathrm{T}$ & $\mathrm{A}$ \\
\hline M. cansus 4 & $\mathrm{C}$ & $\mathrm{T}$ & $\mathrm{T}$ & & & $\mathrm{T}$ & $\mathrm{T}$ & & $\mathrm{T}$ & & & $\mathrm{C}$ & & $\mathrm{A}$ & $\mathrm{C}$ & $\mathrm{T}$ & $\mathrm{T}$ & $\mathrm{T}$ & $\mathrm{A}$ \\
\hline M. cansus 3 & $\mathrm{C}$ & $\mathrm{T}$ & $\mathrm{T}$ & & & $\mathrm{T}$ & $\mathrm{T}$ & & $\mathrm{T}$ & & & & & $\mathrm{A}$ & $\mathrm{C}$ & $\mathrm{T}$ & $\mathrm{T}$ & $\mathrm{T}$ & $\mathrm{A}$ \\
\hline M. rufescens & $\mathrm{C}$ & $\mathrm{T}$ & $\mathrm{T}$ & $\mathrm{T}$ & & & $\mathrm{T}$ & & & & & & $\mathrm{C}$ & $\mathrm{A}$ & & & $\mathrm{T}$ & $\mathrm{C}$ & $\mathrm{A}$ \\
\hline M. rothschildi 1 & $\mathrm{C}$ & $\mathrm{T}$ & $\mathrm{T}$ & $\mathrm{T}$ & & & $\mathrm{T}$ & & & & & & $\mathrm{C}$ & $\mathrm{A}$ & & & $\mathrm{T}$ & $\mathrm{C}$ & $\mathrm{A}$ \\
\hline M. rothschildi 2 & & & $\mathrm{~T}$ & & & $\mathrm{~T}$ & $\mathrm{~T}$ & $\mathrm{~T}$ & & & & $\mathrm{C}$ & & $\mathrm{A}$ & & $\mathrm{G}$ & $\mathrm{T}$ & $\mathrm{T}$ & $\mathrm{A}$ \\
\hline$R$. sinensis & & & $\mathrm{A}$ & & & $\mathrm{T}$ & $\mathrm{C}$ & $\mathrm{T}$ & & $\mathrm{C}$ & & & $\mathrm{C}$ & $\mathrm{T}$ & & & & & $\mathrm{T}$ \\
\hline \multirow[t]{4}{*}{ O. curzoniae } & & & A & & $\mathrm{A}$ & & $\mathrm{C}$ & & & $\mathrm{C}$ & & $\mathrm{C}$ & $\mathrm{C}$ & & $\mathrm{C}$ & $\mathrm{C}$ & $\mathrm{C}$ & $\mathrm{C}$ & $\mathrm{A}$ \\
\hline & 1 & 1 & 1 & 1 & 1 & 1 & 1 & 1 & 1 & 1 & 1 & 1 & 1 & 1 & 1 & 1 & 1 & 1 & 1 \\
\hline & 0 & 0 & 1 & 1 & 1 & 1 & 1 & 2 & 2 & 2 & 2 & 2 & 3 & 3 & 3 & 3 & 3 & 3 & 3 \\
\hline & 7 & 9 & 3 & 5 & 6 & 8 & 9 & 1 & 4 & 7 & 8 & 9 & 0 & 1 & 3 & 4 & 7 & 8 & 9 \\
\hline & $\mathrm{C}$ & $\mathrm{A}$ & $\mathrm{C}$ & $\mathrm{A}$ & $\mathrm{A}$ & $\mathrm{C}$ & $\mathrm{C}$ & $\mathrm{C}$ & $\mathrm{C}$ & $\mathrm{T}$ & $\mathrm{C}$ & $\mathrm{T}$ & A & $\mathrm{A}$ & $\mathrm{T}$ & $\mathrm{C}$ & $\mathrm{A}$ & $\mathrm{T}$ & $\mathrm{C}$ \\
\hline \multicolumn{20}{|l|}{ M. psilurus 2} \\
\hline M. aspalax 1 & & & & $\mathrm{C}$ & & $\mathrm{T}$ & $\mathrm{T}$ & $\mathrm{T}$ & & $\mathrm{C}$ & & & $\mathrm{C}$ & & $\mathrm{C}$ & $\mathrm{T}$ & & & \\
\hline M. fontanieri 2 & & & & & & & & & & $\mathrm{C}$ & & & $\mathrm{C}$ & & $\mathrm{C}$ & $\mathrm{T}$ & & & $\mathrm{T}$ \\
\hline M. fontanieri 3 & & & & & & & & & & $\mathrm{C}$ & & & $\mathrm{C}$ & & $\mathrm{C}$ & $\mathrm{T}$ & & & $\mathrm{T}$ \\
\hline M. fontanieri 4 & & & & & & & & & & $\mathrm{C}$ & & & $\mathrm{C}$ & & $\mathrm{C}$ & $\mathrm{T}$ & & & $\mathrm{T}$ \\
\hline M. baileyi 1 & & & & & & & & & $\mathrm{~T}$ & & & & $\mathrm{C}$ & & & $\mathrm{T}$ & & & $\mathrm{T}$ \\
\hline M. baileyi 2 & & & & & & & & & $\mathrm{~T}$ & & & & $\mathrm{C}$ & & & $\mathrm{T}$ & & & \\
\hline Sailonggu 2 & & & & & & & & & $\mathrm{~T}$ & & & & $\mathrm{C}$ & & & $\mathrm{T}$ & & & \\
\hline Sailonggu 3 & & & & & & & & & $\mathrm{~T}$ & & & & $\mathrm{C}$ & & & $\mathrm{T}$ & & & \\
\hline Sailonggu 1 & & & & & & & & & & & & & $\mathrm{C}$ & & & $\mathrm{T}$ & & & \\
\hline M. cansus 1,2 & & & & & & & & $\mathrm{~A}$ & $\mathrm{~A}$ & $\mathrm{C}$ & & & $\mathrm{C}$ & & & & & & $\mathrm{T}$ \\
\hline M. cansus 4 & & & & & & & & $\mathrm{~A}$ & A & $\mathrm{C}$ & & & $\mathrm{C}$ & & & & & & $\mathrm{T}$ \\
\hline M. cansus 3 & & & $\mathrm{~T}$ & & & & & A & A & $\mathrm{C}$ & & & $\mathrm{T}$ & & & & & & $\mathrm{T}$ \\
\hline M. rufescens & & & $\mathrm{T}$ & & & & & & $\mathrm{T}$ & $\mathrm{C}$ & & & $\mathrm{T}$ & & & $\mathrm{T}$ & & & $\mathrm{T}$ \\
\hline M. rothschildi 1 & & & & & & & & & $\mathrm{~T}$ & $\mathrm{C}$ & & & $\mathrm{C}$ & & & $\mathrm{T}$ & & & $\mathrm{T}$ \\
\hline M. rothschildi 2 & & & & & & & & & $\mathrm{~T}$ & $\mathrm{C}$ & & & $\mathrm{T}$ & $\mathrm{G}$ & & $\mathrm{T}$ & $\mathrm{G}$ & & $\mathrm{T}$ \\
\hline$R$. sinensis & $\mathrm{A}$ & $\mathrm{T}$ & & $\mathrm{T}$ & $\mathrm{G}$ & & $\mathrm{T}$ & $\mathrm{A}$ & $\mathrm{G}$ & & & & $\mathrm{C}$ & & & & & & $\mathrm{T}$ \\
\hline O. curzoniae & & & & & $\mathrm{G}$ & & & $\mathrm{A}$ & A & & $\mathrm{G}$ & $\mathrm{C}$ & $\mathrm{C}$ & & $\mathrm{C}$ & & $\mathrm{G}$ & $\mathrm{C}$ & \\
\hline
\end{tabular}


Table 4. (Continued)

\begin{tabular}{|c|c|c|c|c|c|c|c|c|c|c|c|c|c|c|c|c|c|c|c|}
\hline & $\begin{array}{l}1 \\
4\end{array}$ & 1 & $\begin{array}{l}1 \\
4\end{array}$ & 1 & $\begin{array}{l}1 \\
4\end{array}$ & 1 & $\begin{array}{l}1 \\
5\end{array}$ & 1 & $\begin{array}{l}1 \\
5\end{array}$ & 1 & 1 & 1 & 1 & 1 & 1 & 1 & 1 & $\begin{array}{l}1 \\
7\end{array}$ & 1 \\
\hline & 4 & 4 & 4 & $\begin{array}{l}4 \\
5\end{array}$ & 4 & 4 & $\begin{array}{l}5 \\
1\end{array}$ & 5 & 5 & 5 & 6 & 6 & 6 & $\begin{array}{l}6 \\
5\end{array}$ & 6 & 6 & 6 & 7 & 7 \\
\hline & 0 & 2 & 3 & 5 & 8 & 9 & 1 & 2 & 4 & 7 & 0 & 3 & 4 & 5 & 6 & 7 & 8 & 2 & 5 \\
\hline M. psilurus 1 & $\mathrm{C}$ & A & A & A & $\mathrm{C}$ & $\mathrm{T}$ & A & $\mathrm{C}$ & A & $\mathrm{T}$ & A & $\mathrm{C}$ & $\mathrm{G}$ & $\mathrm{C}$ & $\mathrm{C}$ & $\mathrm{C}$ & A & A & $\mathrm{C}$ \\
\hline \multicolumn{20}{|l|}{ M. psilurus 2} \\
\hline M. aspalax 1 & & & & & $\mathrm{~T}$ & & $\mathrm{~T}$ & & & $\mathrm{C}$ & & & & & & & & & \\
\hline M. fontanieri 2 & & $\mathrm{~T}$ & $\mathrm{C}$ & & & & & $\mathrm{T}$ & & & & & & & & & & & $\mathrm{T}$ \\
\hline M. fontanieri 3 & & $\mathrm{~T}$ & $\mathrm{C}$ & & & & & $\mathrm{T}$ & & & & & & & A & & & & $\mathrm{T}$ \\
\hline M. fontanieri 4 & & $\mathrm{~T}$ & $\mathrm{C}$ & & & & & $\mathrm{T}$ & & & & & & & A & & & & $\mathrm{T}$ \\
\hline M. baileyi 1 & & $\mathrm{C}$ & $\mathrm{C}$ & & A & & & & & $\mathrm{C}$ & & & & & A & & & & \\
\hline M. baileyi 2 & & $\mathrm{C}$ & $\mathrm{C}$ & & $\mathrm{A}$ & & & & & $\mathrm{C}$ & & & & & & & & & \\
\hline Sailonggu 2 & & $\mathrm{C}$ & $\mathrm{C}$ & & A & & & & & $\mathrm{C}$ & & & & & & & & & \\
\hline Sailonggu 3 & & $\mathrm{C}$ & $\mathrm{C}$ & & $\mathrm{A}$ & & & & & $\mathrm{C}$ & & & & & & & & & \\
\hline Sailonggu 1 & & $\mathrm{C}$ & & & A & & & & & $\mathrm{C}$ & & A & & & & & & & \\
\hline M. cansus 1,2 & & $\mathrm{~T}$ & $\mathrm{~T}$ & & $\mathrm{~T}$ & $\mathrm{~A}$ & & & & $\mathrm{C}$ & & & & & & & & $\mathrm{G}$ & $\mathrm{T}$ \\
\hline M. cansus 4 & & $\mathrm{~T}$ & $\mathrm{~T}$ & & $\mathrm{~T}$ & $\mathrm{~A}$ & & & & $\mathrm{C}$ & & & & & & & & & $\mathrm{T}$ \\
\hline M. cansus 3 & & $\mathrm{~T}$ & $\mathrm{~T}$ & & $\mathrm{~T}$ & $\mathrm{~A}$ & & & & $\mathrm{C}$ & & & & & & & & & $\mathrm{T}$ \\
\hline M. rufescens & & $\mathrm{C}$ & $\mathrm{T}$ & & A & & & & & $\mathrm{C}$ & & $\mathrm{T}$ & & & & & & & \\
\hline M. rothschildi 1 & & $\mathrm{C}$ & $\mathrm{T}$ & & A & & & & & $\mathrm{C}$ & & $\mathrm{T}$ & & & & & & & \\
\hline M. rothschildi 2 & & $\mathrm{~T}$ & $\mathrm{~T}$ & & A & & & & & $\mathrm{C}$ & & $\mathrm{T}$ & & & & & & & \\
\hline$R$. sinensis & $\mathrm{T}$ & & $\mathrm{C}$ & $\mathrm{C}$ & $\mathrm{T}$ & & & & $\mathrm{C}$ & & $\mathrm{C}$ & $\mathrm{A}$ & $\mathrm{C}$ & & $\mathrm{T}$ & $\mathrm{A}$ & $\mathrm{T}$ & $\mathrm{C}$ & \\
\hline \multirow[t]{4}{*}{ O. curzoniae } & $\mathrm{G}$ & $\mathrm{C}$ & & & & & $\mathrm{C}$ & & $\mathrm{C}$ & $\mathrm{C}$ & & A & A & A & A & & & & \\
\hline & 1 & 1 & 1 & 1 & 1 & 1 & 1 & 1 & 1 & 1 & 1 & 1 & 2 & 2 & 2 & 2 & 2 & 2 & 2 \\
\hline & 7 & 7 & 8 & 8 & 8 & 8 & 9 & 9 & 9 & 9 & 9 & 9 & 0 & 0 & 0 & 0 & 0 & 1 & 1 \\
\hline & 6 & 8 & 0 & 1 & 4 & 7 & 0 & 1 & 3 & 4 & 6 & 9 & 0 & 2 & 3 & 5 & 8 & 2 & 4 \\
\hline M. psilurus 1 & $\mathrm{C}$ & A & $\mathrm{T}$ & A & $\mathrm{T}$ & $\mathrm{C}$ & A & A & $\mathrm{T}$ & $\mathrm{G}$ & $\mathrm{C}$ & A & $\mathrm{T}$ & $\mathrm{C}$ & $\mathrm{T}$ & A & $\mathrm{C}$ & A & $\mathrm{C}$ \\
\hline M. psilurus 2 & & & & & & & & & & & & & & & & & & & \\
\hline M. aspalax 1 & & & & & $\mathrm{C}$ & & & & & & A & & & $\mathrm{T}$ & $\mathrm{C}$ & & & & \\
\hline M. fontanieri 2 & A & & & & & $\mathrm{T}$ & & & $\mathrm{C}$ & A & & & & & $\mathrm{C}$ & $\mathrm{T}$ & & & \\
\hline M. fontanieri 3 & A & & & & & $\mathrm{T}$ & & & $\mathrm{C}$ & A & & & & & $\mathrm{C}$ & $\mathrm{T}$ & & & \\
\hline M. fontanieri 4 & $\mathrm{~A}$ & & & & & $\mathrm{~T}$ & & & $\mathrm{C}$ & A & & & & & $\mathrm{C}$ & $\mathrm{T}$ & & & \\
\hline M. baileyi 1 & & & & & $\mathrm{C}$ & & & & & A & & & & & $\mathrm{C}$ & & & & \\
\hline M. baileyi 2 & & & & & $\mathrm{C}$ & & & & & $\mathrm{A}$ & & & & & $\mathrm{C}$ & & & & \\
\hline Sailonggu 2 & & & & & $\mathrm{C}$ & & & & & $\mathrm{A}$ & & & & & $\mathrm{C}$ & & & & \\
\hline Sailonggu 3 & & & & & $\mathrm{C}$ & & & & & A & & & & & $\mathrm{C}$ & & & & \\
\hline Sailonggu 1 & & & & & $\mathrm{C}$ & $\mathrm{T}$ & & & $\mathrm{C}$ & A & & & $\mathrm{G}$ & & $\mathrm{C}$ & $\mathrm{G}$ & $\mathrm{T}$ & & \\
\hline M. cansus 1,2 & & & & & $\mathrm{C}$ & & & & & A & & & & & & & & & $\mathrm{T}$ \\
\hline M. cansus 4 & & & & & $\mathrm{C}$ & & & & & A & & & & & & & & & $\mathrm{T}$ \\
\hline M. cansus 3 & & & & & $\mathrm{C}$ & $\mathrm{T}$ & & & & A & & & & & & & & & $\mathrm{T}$ \\
\hline M. rufescens & $\mathrm{T}$ & & & & $\mathrm{C}$ & & & & & A & & $\mathrm{G}$ & & & $\mathrm{C}$ & & $\mathrm{T}$ & & $\mathrm{T}$ \\
\hline$M$. rothschildi 1 & $\mathrm{~T}$ & & & & $\mathrm{C}$ & & & & & A & & $\mathrm{G}$ & & & $\mathrm{C}$ & & $\mathrm{T}$ & & $\mathrm{T}$ \\
\hline M. rothschildi 2 & & & & & & & & & & A & & & & $\mathrm{T}$ & & & $\mathrm{T}$ & & $\mathrm{T}$ \\
\hline$R$. sinensis & & $\mathrm{C}$ & $\mathrm{C}$ & & $\mathrm{C}$ & A & $\mathrm{T}$ & $\mathrm{C}$ & A & A & & & & $\mathrm{T}$ & & & $\mathrm{T}$ & & \\
\hline \multirow[t]{4}{*}{ O. curzoniae } & $\mathrm{A}$ & $\mathrm{G}$ & & $\mathrm{G}$ & $\mathrm{C}$ & & & & $\mathrm{C}$ & A & & & & & & & & $\mathrm{G}$ & $\mathrm{T}$ \\
\hline & 2 & 2 & 2 & 2 & 2 & 2 & 2 & 2 & 2 & 2 & 2 & 2 & 2 & 2 & 2 & 2 & 2 & 2 & 2 \\
\hline & 1 & 1 & 2 & 2 & 2 & 2 & 2 & 2 & 3 & 3 & 3 & 3 & 3 & 3 & 4 & 5 & 5 & 6 & 6 \\
\hline & 5 & 7 & 0 & 2 & 3 & 6 & 7 & 9 & 0 & 2 & 4 & 5 & 6 & 8 & 7 & 3 & 9 & 2 & 6 \\
\hline M. psilurus 1 & $\mathrm{~T}$ & A & $\mathrm{A}$ & $\mathrm{G}$ & $\mathrm{A}$ & $\mathrm{C}$ & $\mathrm{C}$ & $\mathrm{A}$ & $\mathrm{T}$ & $\mathrm{C}$ & $\mathrm{T}$ & $\mathrm{C}$ & $\mathrm{C}$ & $\mathrm{C}$ & $\mathrm{T}$ & $\mathrm{A}$ & $\mathrm{A}$ & $\mathrm{C}$ & $\mathrm{C}$ \\
\hline M. psilurus 2 & & & & & & & & & & & & & & & & & & & \\
\hline M. aspalax 1 & & & & & $\mathrm{~T}$ & & & & & $\mathrm{~T}$ & & & & & & & & & \\
\hline M. fontanieri 2 & $\mathrm{C}$ & & $\mathrm{C}$ & $\mathrm{C}$ & $\mathrm{T}$ & & & $\mathrm{C}$ & & $\mathrm{T}$ & $\mathrm{C}$ & & $\mathrm{T}$ & A & $\mathrm{C}$ & & & & \\
\hline M. fontanieri 3 & $\mathrm{C}$ & & & $\mathrm{C}$ & $\mathrm{T}$ & & & $\mathrm{C}$ & & $\mathrm{T}$ & $\mathrm{C}$ & & $\mathrm{T}$ & A & $\mathrm{C}$ & & & $\mathrm{T}$ & \\
\hline M. fontanieri 4 & $\mathrm{C}$ & & & $\mathrm{C}$ & $\mathrm{T}$ & & & $\mathrm{C}$ & & $\mathrm{T}$ & $\mathrm{C}$ & & $\mathrm{T}$ & A & $\mathrm{C}$ & & & $\mathrm{T}$ & \\
\hline M. baileyi 1 & $\mathrm{C}$ & & & $\mathrm{C}$ & $\mathrm{T}$ & & & $\mathrm{C}$ & & $\mathrm{T}$ & $\mathrm{C}$ & $\mathrm{T}$ & $\mathrm{T}$ & A & & & & $\mathrm{T}$ & \\
\hline M. baileyi 2 & $\mathrm{C}$ & & & $\mathrm{C}$ & $\mathrm{T}$ & & & $\mathrm{C}$ & & $\mathrm{T}$ & $\mathrm{C}$ & $\mathrm{T}$ & $\mathrm{T}$ & A & & & & $\mathrm{T}$ & \\
\hline Sailonggu 2 & $\mathrm{C}$ & & & $\mathrm{C}$ & $\mathrm{T}$ & & & $\mathrm{C}$ & & $\mathrm{T}$ & $\mathrm{C}$ & $\mathrm{T}$ & $\mathrm{T}$ & A & & & & $\mathrm{T}$ & \\
\hline Sailonggu 3 & $\mathrm{C}$ & & & $\mathrm{C}$ & $\mathrm{T}$ & & & $\mathrm{C}$ & & $\mathrm{T}$ & $\mathrm{C}$ & $\mathrm{T}$ & $\mathrm{T}$ & A & & & & $\mathrm{T}$ & \\
\hline Sailonggu 1 & & & & $\mathrm{C}$ & $\mathrm{C}$ & & & $\mathrm{C}$ & & $\mathrm{T}$ & $\mathrm{C}$ & $\mathrm{T}$ & & A & $\mathrm{C}$ & & & $\mathrm{T}$ & \\
\hline M. cansus 1,2 & & & $\mathrm{G}$ & $\mathrm{C}$ & $\mathrm{T}$ & & & & & $\mathrm{T}$ & $\mathrm{C}$ & $\mathrm{T}$ & $\mathrm{T}$ & A & $\mathrm{C}$ & & & $\mathrm{T}$ & \\
\hline M. cansus 4 & & & $\mathrm{G}$ & $\mathrm{C}$ & $\mathrm{T}$ & & $\mathrm{T}$ & & & $\mathrm{T}$ & $\mathrm{C}$ & $\mathrm{T}$ & & A & & & & $\mathrm{T}$ & \\
\hline M. cansus 3 & & & $\mathrm{G}$ & $\mathrm{C}$ & $\mathrm{T}$ & & & & & $\mathrm{T}$ & $\mathrm{C}$ & $\mathrm{T}$ & & A & $\mathrm{C}$ & & & $\mathrm{T}$ & \\
\hline M. rufescens & $\mathrm{C}$ & & & $\mathrm{C}$ & $\mathrm{T}$ & & & $\mathrm{T}$ & & $\mathrm{T}$ & $\mathrm{C}$ & $\mathrm{T}$ & & A & & & & $\mathrm{T}$ & \\
\hline M. rothschildi 1 & $\mathrm{C}$ & & & $\mathrm{C}$ & $\mathrm{T}$ & & & $\mathrm{T}$ & & $\mathrm{T}$ & $\mathrm{C}$ & $\mathrm{T}$ & & A & & & & $\mathrm{T}$ & \\
\hline M. rothschildi 2 & $\mathrm{C}$ & & & $\mathrm{C}$ & $\mathrm{T}$ & & & $\mathrm{C}$ & & $\mathrm{T}$ & $\mathrm{C}$ & $\mathrm{T}$ & & A & & $\mathrm{C}$ & & $\mathrm{T}$ & \\
\hline$R$. sinensis & $\mathrm{C}$ & & & $\mathrm{C}$ & $\mathrm{T}$ & $\mathrm{T}$ & $\mathrm{T}$ & & A & & $\mathrm{C}$ & A & & $\mathrm{T}$ & $\mathrm{C}$ & & & A & $\mathrm{A}$ \\
\hline O. curzoniae & $\mathrm{C}$ & $\mathrm{C}$ & & $\mathrm{C}$ & $\mathrm{C}$ & & & $\mathrm{T}$ & $\mathrm{C}$ & & $\mathrm{C}$ & A & & & $\mathrm{C}$ & & $\mathrm{C}$ & & \\
\hline
\end{tabular}


Table 4. (Continued)

\begin{tabular}{|c|c|c|c|c|c|c|c|c|c|c|c|c|c|c|c|c|c|c|c|}
\hline & 2 & 2 & $\begin{array}{l}2 \\
7\end{array}$ & $\begin{array}{l}2 \\
7\end{array}$ & $\begin{array}{l}2 \\
7\end{array}$ & $\begin{array}{l}2 \\
7\end{array}$ & $\begin{array}{l}2 \\
7\end{array}$ & $\begin{array}{l}2 \\
7\end{array}$ & $\begin{array}{l}2 \\
7\end{array}$ & $\begin{array}{l}2 \\
8\end{array}$ & $\begin{array}{l}2 \\
8\end{array}$ & $\begin{array}{l}2 \\
8\end{array}$ & $\begin{array}{l}2 \\
9\end{array}$ & $\begin{array}{l}2 \\
9\end{array}$ & $\begin{array}{l}2 \\
9\end{array}$ & $\begin{array}{l}3 \\
0\end{array}$ & $\begin{array}{l}3 \\
0\end{array}$ & $\begin{array}{l}3 \\
0\end{array}$ & 3 \\
\hline & 6 & 6 & 7 & 7 & 7 & 7 & 7 & 7 & 7 & 8 & 8 & 8 & 9 & $\begin{array}{l}9 \\
5\end{array}$ & 9 & 0 & 0 & 0 & 1 \\
\hline & 7 & 8 & 1 & 3 & 4 & 5 & 6 & 7 & 8 & 0 & 3 & 6 & 0 & 5 & 9 & 2 & 4 & 7 & 0 \\
\hline M. psilurus 1 & A & $\mathrm{C}$ & A & $\mathrm{T}$ & $\mathrm{C}$ & A & $\mathrm{T}$ & $\mathrm{C}$ & A & $\mathrm{C}$ & $\mathrm{C}$ & A & $\mathrm{C}$ & $\mathrm{C}$ & A & A & A & $\mathrm{C}$ & $\mathrm{C}$ \\
\hline \multicolumn{20}{|l|}{ M. psilurus 2} \\
\hline M. aspalax 1 & & & & & & & & & & & $\mathrm{~T}$ & & & & & & & & \\
\hline M. fontanieri 2 & & & $\mathrm{C}$ & A & $\mathrm{T}$ & $\mathrm{G}$ & & & & & $\mathrm{T}$ & $\mathrm{C}$ & & & & $\mathrm{T}$ & & $\mathrm{T}$ & \\
\hline M. fontanieri 3 & & & $\mathrm{C}$ & A & $\mathrm{T}$ & $\mathrm{G}$ & & & & & $\mathrm{T}$ & $\mathrm{C}$ & & & & $\mathrm{T}$ & & $\mathrm{T}$ & \\
\hline M. fontanieri 4 & $\mathrm{~T}$ & & $\mathrm{C}$ & A & $\mathrm{T}$ & $\mathrm{G}$ & $\mathrm{C}$ & & & & $\mathrm{T}$ & $\mathrm{C}$ & & & & $\mathrm{T}$ & & $\mathrm{T}$ & \\
\hline M. baileyi 1 & $\mathrm{~T}$ & & & & & & & $\mathrm{~T}$ & & $\mathrm{~T}$ & $\mathrm{~T}$ & $\mathrm{~T}$ & $\mathrm{~T}$ & & & $\mathrm{~T}$ & & $\mathrm{~T}$ & $\mathrm{~T}$ \\
\hline M. baileyi 2 & & & & & & & & $\mathrm{~T}$ & & $\mathrm{~T}$ & $\mathrm{~T}$ & $\mathrm{~T}$ & $\mathrm{~T}$ & & & $\mathrm{~T}$ & & $\mathrm{~T}$ & $\mathrm{~T}$ \\
\hline Sailonggu 2 & & & & & & & & $\mathrm{~T}$ & & $\mathrm{~T}$ & $\mathrm{~T}$ & $\mathrm{~T}$ & $\mathrm{~T}$ & & & $\mathrm{~T}$ & & $\mathrm{~T}$ & $\mathrm{~T}$ \\
\hline Sailonggu 3 & & & & & & & & $\mathrm{~T}$ & & $\mathrm{~T}$ & $\mathrm{~T}$ & $\mathrm{~T}$ & $\mathrm{~T}$ & & & $\mathrm{~T}$ & & $\mathrm{~T}$ & $\mathrm{~T}$ \\
\hline Sailonggu 1 & & & & & & & & $\mathrm{~T}$ & & $\mathrm{~T}$ & & $\mathrm{C}$ & $\mathrm{T}$ & & & $\mathrm{T}$ & & & $\mathrm{T}$ \\
\hline M. cansus 1,2 & & & & & $\mathrm{~T}$ & & & & & & $\mathrm{~T}$ & $\mathrm{C}$ & & & & $\mathrm{T}$ & & & \\
\hline M. cansus 4 & & & & & $\mathrm{~T}$ & & & $\mathrm{~T}$ & & & $\mathrm{~T}$ & $\mathrm{C}$ & & & & $\mathrm{T}$ & & & \\
\hline M. cansus 3 & & & & & & & & & & & $\mathrm{~T}$ & $\mathrm{C}$ & & & & $\mathrm{T}$ & & & \\
\hline M. rufescens & & & & & $\mathrm{T}$ & & & $\mathrm{T}$ & & $\mathrm{T}$ & $\mathrm{T}$ & $\mathrm{C}$ & & $\mathrm{T}$ & & $\mathrm{C}$ & & $\mathrm{T}$ & \\
\hline M. rothschildi 1 & & & & & $\mathrm{~T}$ & & & $\mathrm{~T}$ & & $\mathrm{~T}$ & $\mathrm{~T}$ & $\mathrm{C}$ & & $\mathrm{T}$ & & $\mathrm{C}$ & & $\mathrm{T}$ & \\
\hline M. rothschildi 2 & & & & & & & & $\mathrm{~T}$ & $\mathrm{C}$ & $\mathrm{T}$ & $\mathrm{T}$ & & $\mathrm{T}$ & & & $\mathrm{C}$ & & $\mathrm{T}$ & \\
\hline$R$. sinensis & $\mathrm{C}$ & $\mathrm{T}$ & & & & & & $\mathrm{T}$ & & & $\mathrm{T}$ & $\mathrm{C}$ & $\mathrm{G}$ & & & $\mathrm{C}$ & $\mathrm{T}$ & $\mathrm{T}$ & $\mathrm{T}$ \\
\hline \multirow[t]{4}{*}{ O. curzoniae } & & & & & & & & & & $\mathrm{T}$ & & $\mathrm{C}$ & & $\mathrm{A}$ & $\mathrm{T}$ & $\mathrm{C}$ & $\mathrm{C}$ & & \\
\hline & 3 & 3 & 3 & 3 & 3 & 3 & 3 & 3 & 3 & 3 & 3 & 3 & 3 & 3 & 3 & 3 & 3 & 3 & 3 \\
\hline & 1 & 1 & 1 & 1 & 1 & 1 & 1 & 2 & 2 & 2 & 2 & 2 & 2 & 2 & 3 & 3 & 3 & 3 & 3 \\
\hline & 1 & 2 & 3 & 4 & 6 & 7 & 9 & 2 & 3 & 4 & 5 & 6 & 8 & 9 & 1 & 4 & 5 & 6 & 7 \\
\hline M. psilurus 1 & $\mathrm{C}$ & $\mathrm{T}$ & $\mathrm{C}$ & A & $\mathrm{C}$ & A & $\mathrm{T}$ & $\mathrm{C}$ & $\mathrm{G}$ & $\mathrm{T}$ & $\mathrm{C}$ & $\mathrm{C}$ & A & A & A & A & $\mathrm{T}$ & $\mathrm{T}$ & A \\
\hline M. psilurus 2 & & & & & & & & & & & & $\mathrm{~T}$ & & & & & & & \\
\hline M. aspalax 1 & A & $\mathrm{C}$ & & & & & & & A & & & & $\mathrm{C}$ & & & & & & \\
\hline M. fontanieri 2 & & & $\mathrm{~T}$ & & $\mathrm{~T}$ & & & $\mathrm{~T}$ & & $\mathrm{G}$ & $\mathrm{T}$ & & $\mathrm{C}$ & & & & & & \\
\hline M. fontanieri 3 & & & $\mathrm{~T}$ & & $\mathrm{~T}$ & & & $\mathrm{~T}$ & & & $\mathrm{~T}$ & & $\mathrm{C}$ & & & & & & \\
\hline M. fontanieri 4 & & & $\mathrm{~T}$ & & $\mathrm{~T}$ & & & $\mathrm{~T}$ & & & $\mathrm{~T}$ & & $\mathrm{C}$ & & & & & & \\
\hline M. baileyi 1 & & & & & $\mathrm{~T}$ & & $\mathrm{C}$ & $\mathrm{T}$ & A & & $\mathrm{T}$ & & & & & $\underline{\mathrm{C}}$ & & & \\
\hline M. baileyi 2 & & & & & $\mathrm{~T}$ & & $\mathrm{C}$ & $\mathrm{T}$ & A & & $\mathrm{T}$ & & & & & $\underline{\mathrm{C}}$ & & & \\
\hline Sailonggu 2 & & & & & $\mathrm{~T}$ & & $\mathrm{C}$ & $\mathrm{T}$ & & & $\mathrm{T}$ & & & & & $\underline{\mathrm{C}}$ & & & \\
\hline Sailonggu 3 & & & & & $\mathrm{~T}$ & & $\mathrm{C}$ & $\mathrm{T}$ & & & $\mathrm{T}$ & & & & & $\underline{\mathrm{C}}$ & & & \\
\hline Sailonggu 1 & & & & & $\mathrm{~T}$ & & & $\mathrm{~T}$ & & & $\mathrm{~T}$ & & & & & $\overline{\mathrm{C}}$ & & & \\
\hline M. cansus 1,2 & & & & & $\mathrm{~T}$ & & $\mathrm{C}$ & $\mathrm{T}$ & & & & A & & & & & & & \\
\hline M. cansus 4 & & & & & $\mathrm{~T}$ & & $\mathrm{C}$ & $\mathrm{T}$ & & & & A & & & & & & & \\
\hline M. cansus 3 & & & & & $\mathrm{~T}$ & & $\mathrm{C}$ & $\mathrm{T}$ & & & & A & & & & & & & \\
\hline M. rufescens & & & $\mathrm{T}$ & & & & $\mathrm{C}$ & A & & & $\mathrm{T}$ & & $\mathrm{G}$ & & & & & & \\
\hline M. rothschildi 1 & & & $\mathrm{~T}$ & & & & $\mathrm{C}$ & $\mathrm{A}$ & & & $\mathrm{T}$ & & $\mathrm{G}$ & & & & & & \\
\hline$M$. rothschildi 2 & & & $\mathrm{~T}$ & & & & $\mathrm{C}$ & $\mathrm{T}$ & & $\mathrm{G}$ & $\mathrm{T}$ & & $\mathrm{T}$ & & & & & & \\
\hline$R$. sinensis & $\mathrm{T}$ & $\mathrm{C}$ & & & & $\mathrm{C}$ & & & $\mathrm{A}$ & & & $\mathrm{T}$ & $\mathrm{C}$ & $\mathrm{T}$ & G & & & & \\
\hline \multirow[t]{4}{*}{ O. curzoniae } & $\mathrm{T}$ & $\mathrm{C}$ & & $\mathrm{C}$ & & & & A & $\mathrm{A}$ & & $\mathrm{T}$ & & $\mathrm{T}$ & & & & A & $\mathrm{C}$ & $\mathrm{C}$ \\
\hline & 3 & 3 & 3 & 3 & 3 & 3 & 3 & 3 & 3 & 3 & 3 & 3 & 3 & 3 & 3 & 3 & 3 & 3 & \\
\hline & 3 & 3 & 4 & 4 & 4 & 4 & 4 & 4 & 4 & 5 & 5 & 6 & 6 & 6 & 6 & 6 & 6 & 7 & \\
\hline & 8 & 9 & 0 & 1 & 3 & 4 & 6 & 7 & 9 & 5 & 9 & 0 & 1 & 2 & 4 & 8 & 9 & 0 & \\
\hline M. psilurus 1 & G & $\mathrm{C}$ & $\mathrm{C}$ & $\mathrm{G}$ & $\mathrm{C}$ & A & $\mathrm{C}$ & $\mathrm{T}$ & $\mathrm{A}$ & $\mathrm{T}$ & $\mathrm{A}$ & $\mathrm{T}$ & $\mathrm{T}$ & A & A & $\mathrm{C}$ & $\mathrm{T}$ & $\mathrm{C}$ & \\
\hline M. psilurus 2 & & & & & & & & & & & & & & & & & & & \\
\hline M. aspalax 1 & & & & & $\mathrm{~T}$ & & & & & $\mathrm{C}$ & & & $\mathrm{C}$ & & & & & $\mathrm{T}$ & \\
\hline M. fontanieri 2 & & & $\mathrm{~T}$ & & $\mathrm{~T}$ & & $\mathrm{~T}$ & $\mathrm{C}$ & & & & & $\mathrm{C}$ & & & A & & A & \\
\hline M. fontanieri 3 & & & $\mathrm{~T}$ & & $\mathrm{~T}$ & & $\mathrm{~T}$ & $\mathrm{C}$ & & & & & $\mathrm{C}$ & & & A & & A & \\
\hline M. fontanieri 4 & & & $\mathrm{~T}$ & & $\mathrm{~T}$ & & $\mathrm{~T}$ & $\mathrm{C}$ & & & & & $\mathrm{C}$ & & & A & & A & \\
\hline M. baileyi 1 & & & $\mathrm{~T}$ & & $\mathrm{~T}$ & & $\mathrm{~T}$ & $\mathrm{C}$ & & & & & $\mathrm{C}$ & & & A & & & \\
\hline M. baileyi 2 & & & $\mathrm{~T}$ & & $\mathrm{~T}$ & & $\mathrm{~T}$ & $\mathrm{C}$ & & & & & $\mathrm{C}$ & & & A & & & \\
\hline Sailonggu 2 & & & $\mathrm{~T}$ & & & & $\mathrm{~T}$ & $\mathrm{C}$ & & $\mathrm{C}$ & & & $\mathrm{C}$ & & & A & & & \\
\hline Sailonggu 3 & & & $\mathrm{~T}$ & & & & $\mathrm{~T}$ & $\mathrm{C}$ & & & & & $\mathrm{C}$ & & & $\mathrm{A}$ & & & \\
\hline Sailonggu 1 & & & $\mathrm{~T}$ & & $\mathrm{~T}$ & & $\mathrm{~T}$ & $\mathrm{C}$ & & $\mathrm{C}$ & & & $\mathrm{C}$ & & & A & & & \\
\hline M. cansus 1,2 & & & $\mathrm{~T}$ & & & & $\mathrm{~T}$ & $\mathrm{C}$ & & & & & $\mathrm{C}$ & & & A & & & \\
\hline M. cansus 4 & & & $\mathrm{~T}$ & & & & $\mathrm{~T}$ & $\mathrm{C}$ & & & & & $\mathrm{C}$ & & & A & & & \\
\hline M. cansus 3 & & & $\mathrm{~T}$ & & & & $\mathrm{~T}$ & $\mathrm{C}$ & & & & & $\mathrm{C}$ & & & A & & & \\
\hline M. rufescens & & & & & & & $\mathrm{T}$ & $\mathrm{C}$ & & $\mathrm{C}$ & & & $\mathrm{C}$ & & & $\mathrm{G}$ & & & \\
\hline M. rothschildi 1 & & & & & & & $\mathrm{~T}$ & $\mathrm{C}$ & & $\mathrm{C}$ & & & $\mathrm{C}$ & & & $\mathrm{G}$ & & & \\
\hline M. rothschildi 2 & & & $\mathrm{~T}$ & & & & & $\mathrm{C}$ & & & & & $\mathrm{C}$ & & & A & & $\mathrm{T}$ & \\
\hline$R$. sinensis & & & $\mathrm{T}$ & & $\mathrm{T}$ & & A & & & $\mathrm{C}$ & & $\mathrm{C}$ & $\mathrm{C}$ & & & $\mathrm{T}$ & & $\mathrm{T}$ & \\
\hline O. curzoniae & $\mathrm{T}$ & $\mathrm{G}$ & & A & & $\mathrm{C}$ & A & A & $\mathrm{T}$ & $\mathrm{C}$ & $\mathrm{C}$ & & & $\mathrm{C}$ & $\mathrm{C}$ & $\mathrm{T}$ & $\mathrm{G}$ & A & \\
\hline
\end{tabular}


Table 4. (Continued)

$\begin{array}{llllll}\text { CACCCCAGCA } & \text { AACCCACTTA } & \text { ACACACCACC } & \text { ACATATCAAA } & \text { CCAGAATGAT } & \text { ATTTCCTCTT } \\ \text { CGCCTACGCA } & \text { ATCCTACGCT } & \text { CTATTCCCAA } & \text { TAAACTAGGA } & \text { GGAGTCCTAG } & \text { CCCTAATCCT } \\ \text { CTCCATTCTA } & \text { ATTCTAATCC } & \text { TAATACCCCT } & \text { ACTACATACA } & \text { TCCGCCCAAC } & \text { GAAGCCTAAT } \\ \text { ATTTCGCCCA } & \text { ATTGGCCAAT } & \text { GCTTATTCTG } & \text { AATCTTAGTA } & \text { GGAGACCTAT } & \text { TCATCCTCAC } \\ \text { ATGAATTGGA } & \text { GGACAACCAG } & \text { TCGAACACCC } & \text { ATTCATCATC } & \text { ATCGGACAAC } & \text { TAGCCTCAAT } \\ \text { CATATACTTC } & \text { CTCATCATTC } & \text { TCGTCCTAAT } & \text { ACCATTAGCC } & \text { GGCATCTTAG } & \text { AAAATAAAAT } \\ \text { TATAAAACTC } & & & & & \end{array}$

Mutational sites and specific diagnostic sites (underlined below the capital) used to authenticate crude drug Sailonggu are indicated in the Table, with the 370 bp fragment sequence of M. psilurus listed below.

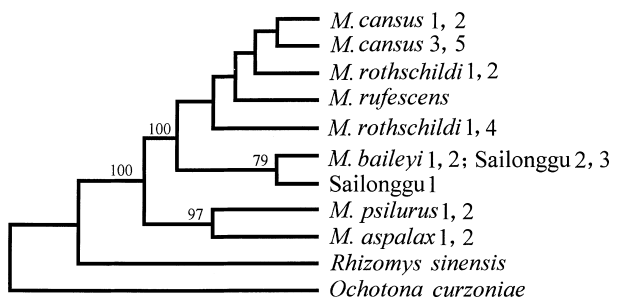

Fig. 1. UPGMA Tree for Mitochondrial 12S rRNA Gene Fragments of Sailonggus and Original Animals of Zokors Based on Kimura's 2-Parameter Distance

Bootstrap values $<50 \%$ were not shown.

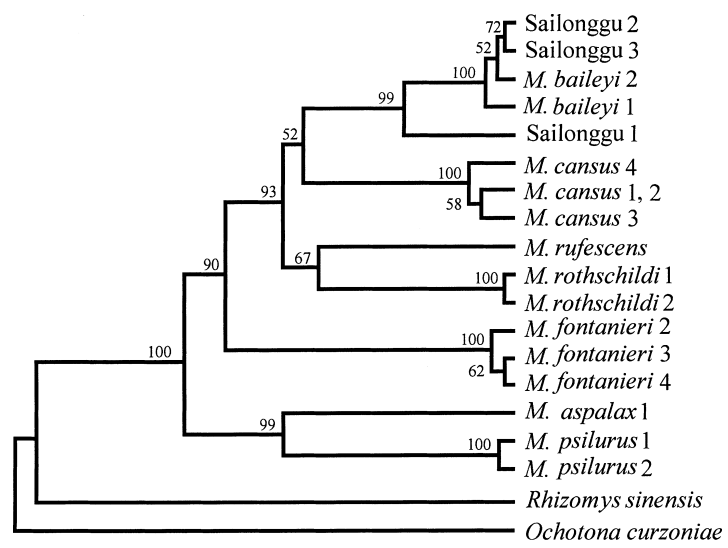

Fig. 2. UPGMA Tree for Mitochondrial Cyt $b$ Gene Fragments of Sailonggus and Original Animals of Zokors Based on Kimura's 2-Parameter Distance

Bootstrap values $<50 \%$ were not shown

the 12S rRNA, and 0.005 to 0.079 in the Cyt $b$ gene sequences, respectively. Both are the smallest compared with those between the crude drugs and the original animals of other species of zokors in the present study.

Phylogenetic Analysis UPGMA analysis of the datasets of $12 \mathrm{~S}$ and cyt $b$ gene sequences resulted in very similar topologies (Figs. 1, 2). The original animals of M. baileyi and Sailonggu clustered to a clade with a high value of nodal support in both trees. The results of phylogenetic analysis based on the two gene fragments also support that all of the crude drug samples tested are made of the bone of $M$. baileyi.

Diagnostic PCR In the diagnostic assay, using universal primer L1091 and H1478, we amplified a 387 bp fragment of the mitochondrial $12 \mathrm{~S}$ rRNA gene for positive controls from 16 samples (Fig. 3a). While using the allele-specific primers SL1L/SL1H and SL2L/SL2H for PCR, $338 \mathrm{bp}$ and $320 \mathrm{bp}$ amplified DNA fragments, respectively, were obtained from
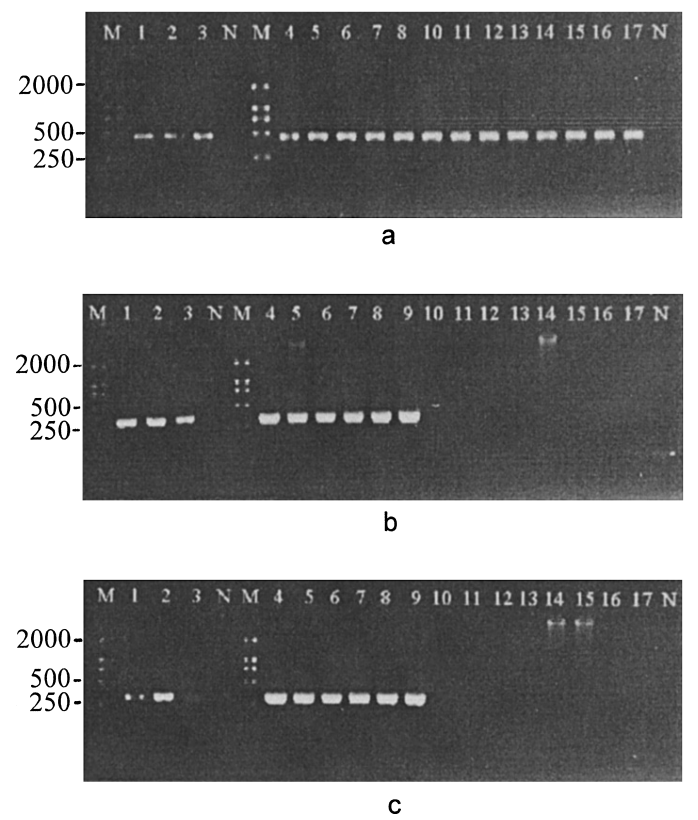

Fig. 3. Agarose Gel Electrophoresis of PCR Identification of Original Animals and Crude Drug Sailonggu

a: Positive controls annealing at $55^{\circ} \mathrm{C}$ for all DNA templates resolved by $2.0 \%$ agarose gel electrophoresis. b: Agarose gel electrophoresis of PCR products of $12 \mathrm{~S}$ rRNA fragment from original animals, and crude drug Sailonggu samples using primers SL1L and SL1H annealed at $65^{\circ} \mathrm{C}$. c: Agarose gel electrophoresis of PCR products of Cyt $b$ fragment from original animals and crude drug Sailonggu samples using primers SL2L and SL2H annealed at $65^{\circ} \mathrm{C}$. N: Negative control without DNA template; M: DNA marker, DL2000 (Takara). 9: including $1 \mathrm{ml}$ templates of No. 4 and $1 \mathrm{ml}$ mixture templates of No. 10,11 and 12. Other codes are identical to those in Table 1. The sizes of No. 1, 2 and 3 in b look different from each other, but this is due to the higher gel well position for the latter two, respectively.

Sailonggu and original animal M. baileyi. No specific PCR product was obtained from the other animals using the allelespecific primers (Figs. 3b, c). These results were reproducible until annealing temperature increased to $68^{\circ} \mathrm{C}$.

\section{DISCUSSION}

We tested the possibility of authentication of the crude drug Sailonggu by sequence alignment and phylogenetic analysis. Two diagnostic sites were found in both $12 \mathrm{~S}$ and cyt $b$ for authentication of Sailonggu. However, only a limited number of individuals of $M$. baileyi and other zokor species were sampled in this study. Therefore, sequence alignment will not be an accurate tool for identification of the crude drug before a significant sequence database has been built. Although sequence variations of the $12 \mathrm{~S}$ and cyt $b$ fragments were found among the samples of Sailonggu and the original animal of $M$. baileyi, the UPGMA trees support that all three 
crude drug samples are of the genuine drug Sailonggu.

DNA of the crude drugs was degraded during the preparation, transportation and storage of the medicinal materials. However, sufficient DNA was obtained for authentication. ${ }^{12-14)}$ The two pairs of diagnostic primers we designed match exactly with the definite DNA nucleotide sequences of Myospalax baileyi, but incompletely with the sequences of templates from other species of zokors. Therefore, the PCR performed with these two pairs of primers is a site specific PCR. Theoretically, the annealing temperature of the diagnostic primers is above $80^{\circ} \mathrm{C}$. It is important for diagnostic PCR that the $3^{\prime}$ end of the primers should be mismatched with the sequences of the substitutes or adulterants in order to not amplify their DNA templates under the high temperature condition. A high-stringency PCR reaction with each one pair of primers specific for $M$. baileyi will give a positive result only from the template DNA of genuine crude drugs, and a negative result from that of substitutions. However, a negative result could also be produced from poor quality substitutes or adulterants' DNA, or good quality of genuine drugs' DNA. Therefore, amplification of positive controls using universal primers prior to the diagnostic PCR is necessary. In this study, all template DNAs were amplified using universal primers at $55^{\circ} \mathrm{C}$ annealing temperature. All PCR under this condition produced clear bands on agarose gel electrophoresis (Fig. 3). The result indicated that the DNA templates used are suitable for PCR. It also indicated that a particular DNA band should be amplified from these templates using diagnostic primers if the primer can find an appropriate annealing position on the template DNA. On the other hand, if the diagnostic primers fail to match the template, especially at the $3^{\prime}$ end of the primers, the reaction will give a negative result. Our results indicate that Sailonggu samples could be definitely distinguished from its substitutes or adulterants by diagnostic PCR using any one pair of the diagnostic primers annealing at $65-68^{\circ} \mathrm{C}$. In addition, the result will not be influenced by exo-DNA, because the diagnostic primers are specific for Sailonggu only, and the reaction is performed under high-stringency conditions.

Among the three methods tested, the sequencing method is far more complicated compared with the PCR method, and the phylogenetic analysis method is based on DNA se- quences. On the other hand, the allele-specific diagnostic PCR method has several advantages: 1) Only a small quantity of sample is required for identification; 2) the process is simple and inexpensive; 3 ) the result will not be affected by contamination in samples, and offers an accurate identification. Therefore, we believe the PCR method is a useful tool for the quality control of Chinese crude drugs.

Acknowledgments We thank Q. Y. Wang for his assistance in the collection of samples, and Professors H. Cao, N. C. Fan, Y. Q. Ma and T. Z. Wang for their support during the study. We give our thanks to the staff of the Institute of Genetic Resources, College of Life Sciences, Nanjing Normal University for their kind assistance. This work was supported by a grant from Beijing Tongrentang Medicine Industry Limited Group to KYZ.

\section{REFERENCES}

1) Chen G. T. (ed.), “Complete Explanation of Bencaogangmu,” Vol. 2, Xuyuan Press, Beijing, 1992.

2) Ye B. L., Guo P. J., "Medicinal Animals of Qinghai-Tibet Plateau," Shaanxi Press, Xian, 1998.

3) Wang J., New Med. Shaanxi, 2, 51-54 (1975).

4) Zhang B. Z., Chin. J. Inf. Tradit. Chin. Med., 3, 38 (1996).

5) Huang W. J. Chen Y. X., Wen Y. X., "Glires in China," Fudan University Press, Shanghai, 1995.

6) Wang Y. Q., Zhou K. Y., "Authentication of Chinese Medicinal Materials by DNA Technology," Chap. 8, eds. by Shaw P. C., Wang J., But P. P.-H., World Scientific, New Jersey, 2002, pp. 125-153.

7) Sambrook J., Fritsch E. F., Maniatis T., "Molecular Cloning. A Laboratory Manual," 2nd ed., Cold Spring Harbor Laboratory Press, Cold Spring Harbor, New York, 1989.

8) Kocher T. D., Thomas W. K., Meyer A., Edwards A., Pääbo S., Villablanca F. X., Wilson A. C., Proc. Natl. Acad. Sci. U.S.A., 86, 6196$6200(1989)$.

9) Thompson J. D., Gibson T. J., Plewniak F., Jeanmougin F., Higgins D. J., Nucleic Acids Res., 25, 4876 - 4882 (1997).

10) Kimura M., J. Mol. Evol., 16, 111-120 (1980).

11) Kumar S., Tamura K., Jakobsen I. B., Nei M., Bioinformatics, 17, 1244-1245 (2001).

12) Wang Y. Q., Zhou K. Y., Xu L. S., Dong T. T. X., Tsim K. W. K., Biol. Pharm. Bull., 23, 585-588 (2000).

13) Wang Y. Q., Zhou K. Y., Acta Pharm. Sin., 32, 384-387 (1997).

14) Liu Z. Q., Wang Y. Q., Zhou K. Y., Han D. M., Yang X. G., LIU X. H., Planta Medica, 67, 385-387 (2001). 